\title{
Maximizing Headgroup Repulsion: Hybrid Surfactants with Ultrahighly Charged Inorganic Heads and Their Unusual Self- Assembly
}

\author{
Alexander Klaiber, ${ }^{\dagger}$ Cornelia Lanz, $^{\dagger}$ Steve Landsmann, $^{\dagger}$ Julia Gehring, $^{\dagger}$ Markus Drechsler, ${ }^{\ddagger}$ \\ and Sebastian Polarz ${ }^{*}$, \\ ${ }^{\dagger}$ Department of Chemistry, University of Konstanz, D-78457 Konstanz, Germany \\ ${ }^{\ddagger}$ Laboratory for Soft-Matter Electron Microscopy, University of Bayreuth, D-95440 Bayreuth, Germany
}

Supporting Information

\begin{abstract}
Nonequilibrium states of matter are arousing huge interest because of the outstanding possibilities to generate unprecedented structures with novel properties. Selforganizing soft matter is the ideal object of study as it unifies periodic order and high dynamics. Compared to settled systems, it becomes vital to realize more complex interaction patterns. A promising and intricate approach is implementing controlled balance between attractive and repulsive forces. We try to answer a fundamental question in surfactant science: How are processes like lyotropic liquid crystals and micellization affected, when headgroup charge becomes so

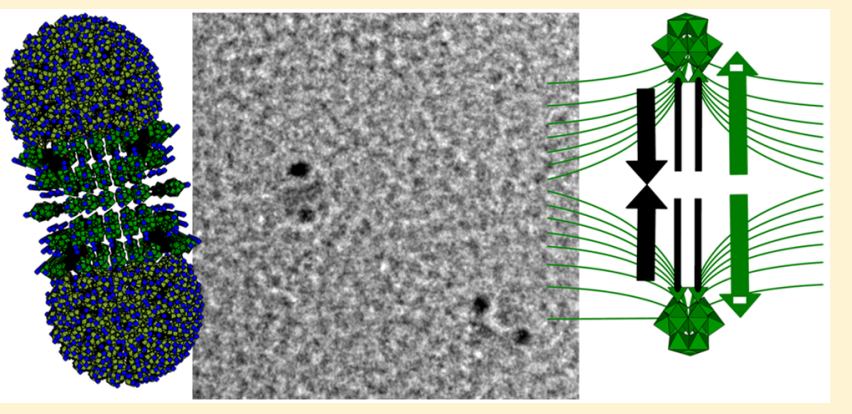
large that repulsive interactions are inevitable? A particular challenge is that size and shape of the surfactant must not change. We could realize the latter by means of new hybrid surfactants with a heteropolyanion head $\left[\mathrm{EW}_{11} \mathrm{O}_{39}\right]^{n-}\left(\mathrm{E}=\mathrm{P}^{\mathrm{V}}, \mathrm{Si}^{\mathrm{IV}}, \mathrm{B}^{\mathrm{III}} ; n=3,4,5\right)$. Among the unusual self-assembled structures, we report a new type of micelle with dumbbell morphology.
\end{abstract}

\section{INTRODUCTION}

The spontaneous formation of organized patterns as an intrinsic property of a system containing discrete constituents, a process termed self-assembly, ${ }^{1,2}$ has fascinated scientist in all fields because entropy commonly leads to disorder. Nature displays the enormous potential of self-organization attributed to many of the unexcelled properties of biological matter; for example, self-repair originates from the ability to achieve selfassembly. ${ }^{3}$ In materials science, full exploration of this potential has still not been achieved, and for the next level, which is programmable self-assembly, we need to learn how to encode more complex interaction. For nanoparticles, Cademartiri discussed the latter aspect in $2015 .^{4}$ One learns that a straightforward approach for finding unique self-assembled structures is to implement long-range and highly directional repulsive forces in addition to the attractive interactions, which are responsible for aggregation first.

A special class of self-assembled materials is given by liquid crystals. They unify structural order and a high degree of mobility. These special features lead to a plethora of fascinating properties as also stated in the seminal article published by Tschierke in $2013 .^{5}$ Liquid crystals are formed by unique molecular compounds, and one can roughly distinguish between thermotropic and lyotropic liquid crystals (LLCs). LLCs and, at lower concentration, micellization rely on amphiphiles, most importantly surfactants. Surfactants are low-molecular-weight compounds comprising a hydrophilic headgroup, often charged, attached to at least one alkyl-chain of medium length $\left(\mathrm{C}_{12}-\mathrm{C}_{20}\right)$ as a hydrophobic entity. An important variable in surfactant science is the so-called packing parameter, a number describing roughly the shape of the molecule. On programmed self-assembly in the sense discussed above, there exists a substantial limitation: Intermolecular interactions cannot be tuned without substantially changing the morphology and solvent compatibilities of the surfactant at the same time. For instance, although the role of the charge of the headgroup has been discussed intensely ${ }^{6,7}$ for classical, organic surfactants, one can hardly extend the charge to values larger than 2 without significantly altering the packing parameter. What one can do is to increase the number of charged functionalities, but an additional headgroup will of course alter the molecular shape significantly. Therefore, for any effect, it would be unclear if this is due to the charge, the altered packing parameter, or both. Surfactants with varying charge but constant shape are needed.

In our paper, we will report about the synthesis of such surfactants with highly charged head, and we will investigate the self-assembled structures formed at different concentrations in

\footnotetext{
Received: July 19, 2016

Revised: September 29, 2016

Published: October 3, 2016
} 
water. The redox states of transition-metal compounds are variable. Thus, one could imagine obtaining differently charged surfactants without changing their shape, when such transitionmetal containing entities are used as head groups. ${ }^{8}$ However, an important question is, which kind of "inorganic moiety" is most suitable for our purpose. Recently, we presented a prototype for hybrid surfactants (denoted as $\mathrm{PW}_{11} \mathrm{C}_{16}$ ) containing a polyoxometalate (POM) headgroup $\left[\mathrm{PW}_{11} \mathrm{O}_{39}\right]^{3-8-11}$ It was synthesized starting from a so-called lacunary Keggin ion $\left[\mathrm{PW}_{11} \mathrm{O}_{39}\right]^{7-}$ (see also Figure 1). ${ }^{9}$ Because lacunary compounds exist not only for phosphorus but also for other elements $\mathrm{E}$ in the center of the oxo-cluster $(\mathrm{E}=\mathrm{Si}(\mathrm{IV})$, $\mathrm{B}(\mathrm{III})),{ }^{12}$ our idea is to prepare a systematic series of surfactants with identical structure but different overall charge and to examine the effect of the increasing charge on selfassembly.

\section{EXPERIMENTAL SECTION}

Synthesis Methods. The lacunary polyoxometalates $\mathrm{K}_{7}\left[\mathrm{PW}_{11} \mathrm{O}_{39}\right],{ }^{13} \mathrm{~K}_{8}\left[\mathrm{SiW}_{11} \mathrm{O}_{39}\right]$, ${ }^{14}$ and $\mathrm{K}_{8} \mathrm{H}\left[\mathrm{BW}_{11} \mathrm{O}_{39}\right]{ }^{15}$ were synthesized according to the literature.

Synthesis of $\mathrm{TMA}_{3}\left[\mathrm{PW}_{11} \mathrm{O}_{40}\left(\mathrm{SiC}_{16} \mathrm{H}_{33}\right)_{2}\right]$. In a $5 \mathrm{~L}$ beaker, $5.00 \mathrm{~g}$ of powdered $\mathrm{K}_{7}\left[\mathrm{PW}_{11} \mathrm{O}_{39}\right] \cdot 14 \mathrm{H}_{2} \mathrm{O}(1.56 \mathrm{mmol})$ was dissolved in $5 \mathrm{~L}$ of acetonitrile. To the resulting suspension, $3.67 \mathrm{mmol}$ of hexadecyltrimethoxysilane, 4.4 eq of $1 \mathrm{M} \mathrm{HCl}(7.34 \mathrm{~mL})$, and 7.5 eq of tetramethylammonium chloride were added and stirred for $24 \mathrm{~h}$ at room temperature. After filtration and removal of the solvent, the resulting white precipitate was collected and washed with water, methanol, and diethyl ether ( $50 \mathrm{~mL}$ each). Yield: $2.83 \mathrm{~g}$ (53\% based on $\left.\mathrm{K}_{7}\left[\mathrm{PW}_{11} \mathrm{O}_{39}\right]\right)$, white powder.

${ }^{1} \mathrm{H}$ NMR (DMSO-d6): $\delta=3.23(\mathrm{~s}, 36 \mathrm{H}), 1.62-1.08(\mathrm{~m}, 56 \mathrm{H})$, $0.85(\mathrm{t}, J=6.7,6 \mathrm{H}), 0.71(\mathrm{t}, J=7.5,4 \mathrm{H}) .{ }^{29} \mathrm{Si}$ NMR (DMSO-d6): $\delta=$ -51.20. ${ }^{31} \mathrm{P}$ NMR (DMSO-d6): $\delta=-13.83 .{ }^{183} \mathrm{~W}-\mathrm{NMR}(25 \mathrm{MHz}$, acetonitrile-d3): $\delta=-103.16(\mathrm{~d}, J=1.0 \mathrm{~Hz}, 2 \mathrm{~W}),-108.71(\mathrm{~d}, J=1.0$ $\mathrm{Hz}, 2 \mathrm{~W}),-112.78$ (d, $J=1.5 \mathrm{~Hz}, 1 \mathrm{~W}),-124.63(\mathrm{~d}, J=1.2 \mathrm{~Hz}, 2 \mathrm{~W})$, $-202.35(\mathrm{~d}, J=1.6 \mathrm{~Hz}, 2 \mathrm{~W}),-253.96(\mathrm{~d}, J=1.4 \mathrm{~Hz}, 2 \mathrm{~W})$. IR (ATR): 1111 ( $\mathrm{Si}-\mathrm{O}-\mathrm{Si}$ ), 1063 (P-O), 1051 (P-O), 1033 (P-O), 981, (W = O), $959(\mathrm{sh}, \mathrm{W}=\mathrm{O}), 951(\mathrm{~W}=\mathrm{O}), 861(\mathrm{~W}-\mathrm{O}-\mathrm{W}), 810(\mathrm{~W}-\mathrm{O}-$ $\mathrm{W}), 776(\mathrm{~W}-\mathrm{O}-\mathrm{W}), 747(\mathrm{~W}-\mathrm{O}-\mathrm{W}), 704(\mathrm{~W}-\mathrm{O}-\mathrm{W})$. Elemental analysis $\mathrm{C}, \mathrm{H}, \mathrm{N}: 15.47 \%, 3.1 \%, 1.23 \%$.

Synthesis of $\mathrm{TMA}_{4}\left[\mathrm{SiW}_{11} \mathrm{O}_{40}\left(\mathrm{SiC}_{16} \mathrm{H}_{33}\right)_{2}\right]$. In a $5 \mathrm{~L}$ beaker $5.00 \mathrm{~g}$ of powdered $\mathrm{K}_{8}\left[\alpha-\mathrm{SiW}_{11} \mathrm{O}_{39}\right] \cdot 13 \mathrm{H}_{2} \mathrm{O}(1.56 \mathrm{mmol})$ was dissolved in $5 \mathrm{~L}$ of acetonitrile. To the resulting suspension, $3.67 \mathrm{mmol}$ of hexadecyltrimethoxysilane, 4.4 eq of $1 \mathrm{M} \mathrm{HCl}(7.34 \mathrm{~mL})$, and 7.5 eq of tetramethylammonium chloride were added and stirred for $24 \mathrm{~h}$ at room temperature. After filtration and removal of the solvent, the resulting white precipitate was collected and washed with water, methanol, and diethyl ether (50 mL each). Yield: $4.57 \mathrm{~g}$ ( $84 \%$ based on $\left.\mathrm{K}_{8}\left[\alpha-\mathrm{SiW}_{11} \mathrm{O}_{39}\right]\right)$, white powder.

${ }^{1} \mathrm{H}$ NMR (DMSO-d6): $\delta=3.23(\mathrm{~s}, 48 \mathrm{H}), 1.62-1.08(\mathrm{~m}, 56 \mathrm{H})$, $0.86(\mathrm{t}, J=6.7,6 \mathrm{H}), 0.56(\mathrm{t}, J=7.5,4 \mathrm{H}) .{ }^{29} \mathrm{Si}$ NMR (DMSO-d6): $\delta=$ $-52.32,-85.11 .{ }^{183} \mathrm{~W}-\mathrm{NMR}(25 \mathrm{MHz}$, acetonitrile-d3): $\delta=-112.77$ (2W), $-116.69(2 \mathrm{~W}),-119.91(1 \mathrm{~W}),-133.43(2 \mathrm{~W}),-180.09(2 \mathrm{~W})$, $-257.37(2 \mathrm{~W})$. Elemental analysis $\mathrm{C}, \mathrm{H}, \mathrm{N}: 16.50 \%, 3.29 \%, 1.60 \%$.

Synthesis of $\mathrm{TMA}_{5}\left[\mathrm{BW}_{11} \mathrm{O}_{40}\left(\mathrm{SiC}_{16} \mathrm{H}_{33}\right)_{2}\right]$. In a $5 \mathrm{~L}$ beaker, $5.00 \mathrm{~g}$ of powdered $\mathrm{K}_{8} \mathrm{H}\left[\alpha-\mathrm{BW}_{11} \mathrm{O}_{39}\right] \cdot 13 \mathrm{H}_{2} \mathrm{O}(1.56 \mathrm{mmol})$ was dissolved in 5 $\mathrm{L}$ of acetonitrile. To the resulting suspension, $3.67 \mathrm{mmol}$ of hexadecyltrimethoxysilane, 4.4 eq of $1 \mathrm{M} \mathrm{HCl}(7.34 \mathrm{~mL})$, and 7.5 eq of tetramethylammonium chloride were added and stirred for $24 \mathrm{~h}$ at room temperature. After filtration and removal of the solvent, the resulting white precipitate was collected and washed with water, methanol, and diethyl ether ( $50 \mathrm{~mL}$ each). Yield: $4.2 \mathrm{~g}$ (76\% based on $\left.\mathrm{K}_{8} \mathrm{H}\left[\alpha-\mathrm{BW}_{11} \mathrm{O}_{39}\right]\right)$, white powder.

${ }^{1} \mathrm{H}$ NMR (DMSO-d6): $\delta=3.23(\mathrm{~s}, 51 \mathrm{H}), 1.62-1.08(\mathrm{~m}, 56 \mathrm{H})$, $0.85(\mathrm{t}, J=6.7,6 \mathrm{H}), 0.62(\mathrm{t}, J=7.5,4 \mathrm{H}) .{ }^{11} \mathrm{~B}$ NMR (DMSO-d6): $\delta=$ 1.89. ${ }^{29} \mathrm{Si}$ NMR (DMSO-d6): $\delta=-49.00$. Elemental analysis $\mathrm{C}, \mathrm{H}, \mathrm{N}$ : $17.59 \%, 3.58 \%, 1.97 \%$.
Ion Exchange to the Corresponding $\mathrm{H}$ - and $\mathrm{Na}$ $\left[X W_{11} \mathrm{O}_{40}\left(\mathrm{SiC}_{16} \mathrm{H}_{33}\right)_{2}\right]$. Cations were exchanged to $\mathrm{Na}^{+}$by slow filtration of a $5 \mathrm{mg} / \mathrm{mL}$ solution of TMA-POM through a column packed with Amberlite-IR120-H/Na. Complete exchange was confirmed via ${ }^{1} \mathrm{H}$ NMR (absence of signal at $\delta=3.23 \mathrm{ppm}$ ).

Analytical Methods. NMR measurements $\left({ }^{1} \mathrm{H},{ }^{11} \mathrm{~B},{ }^{13} \mathrm{C},{ }^{29} \mathrm{Si},{ }^{31} \mathrm{P}\right)$ were performed on a Varian Unity INOVA 400 Spectrometer. The ${ }^{183} \mathrm{~W}$-NMR-spectra were recorded on a Bruker Avance III $600 \mathrm{MHz}$ Spectrometer with $10 \mathrm{~mm}$ NMR tubes. ESI-MS data were acquired on a Bruker microtof II system. The solutions were injected directly into the evaporation chamber. SAXS was acquired on a Bruker Nanostar system equipped with pinhole collimation and $\mathrm{Cu} \mathrm{K} \alpha$ radiation. The samples were placed between X-ray transparent mylar foils and were measured in an evacuated chamber. For avoiding the contamination of the measurement chamber, samples were dried prior to use. Liquid samples were sealed in a $1 \mathrm{~mm}$ Mark-tubes made of soda lime glass. Modeling of liquid cell data was performed using the SASView software (developed by the DANSE project under NSF award DMR0520547). Textures of liquid-crystalline samples were studies with an Olympus CX41 light microscope. TEM was acquired on a Zeiss Libra 120 system and a JEOL JEM-2200FS. The dry sample was placed directly on carbon-coated copper grids. For cryo transmission electron microscopy studies, a sample droplet of $2 \mathrm{ul}$ was put on a lacey carbon filmed copper grid (Science Services, Muenchen), which was hydrophilized by air plasma glow discharge unit (30s with $50 \mathrm{~W}$, Solarus 950, Gatan, Muenchen, Germany). Subsequently, most of the liquid was removed with blotting paper in a Leica EM GP (Wetzlar, Germany) grid plunge device, leaving a thin film stretched over the lace holes in the saturated water atmosphere of the environmental chamber. The specimens were instantly shock frozen by rapid immersion into liquid ethane cooled to approximately $97 \mathrm{~K}$ by liquid nitrogen in the temperature-controlled freezing unit of the Leica EM GP. The temperature was monitored and kept constant in the chamber during all the sample preparation steps. The specimen was inserted into a cryotransfer holder (CT3500, Gatan, Muenchen, Germany) and transferred to a Zeiss/LEO EM922 Omega EFTEM (Zeiss Microscopy GmbH, Jena, Germany). Examinations were carried out at temperatures around $95 \mathrm{~K}$. The TEM was operated at an acceleration voltage of $200 \mathrm{kV}$. Zero-loss filtered images $(\Delta E=0 \mathrm{eV})$ were taken under reduced dose conditions $\left(100-1000 \mathrm{e} / \mathrm{nm}^{2}\right)$. All images were registered digitally by a bottom mounted CCD camera system (Ultrascan 1000, Gatan, Muenchen, Germany) combined and processed with a digital imaging processing system (Digital Micrograph GMS 1.9, Gatan, Muenchen, Germany). Collected images were processed with a background-subtraction routine, and where appropriate, a smoothing filter (Butterworth Filter) was applied to reduce noise. IR-spectroscopy was performed on a PerkinElmer 100 system. Dynamic light scattering was measured on a Viscotek 802 DLS machine. Raman measurements were performed on a PerkinElmer Ramanstation 400.

\section{RESULTS AND DISCUSSION}

Molecular Synthesis of Surfactants with Ultrahigh Head Group Charge. Based on our work on surfactants with $\mathrm{a}\left[\mathrm{PW}_{11} \mathrm{O}_{39}\right]^{3-}$ head, ${ }^{8-11}$ the main aim of the current work is to increase the charge of the head by synthesizing new surfactants containing $\left[\mathrm{SiW}_{11} \mathrm{O}_{39}\right]^{4-}$ and $\left[\mathrm{BW}_{11} \mathrm{O}_{39}\right]^{5-}$ moieties. Because only the central element is varied, we expect that only charge differs and molecular shape remains constant. The latter was one of the key goals formulated in the Introduction section of this paper.

Three surfactants $\mathrm{EW}_{11} \mathrm{C}_{16}$ were prepared by condensation of two alkylsilanes to the cavity of the lacunary species $\left[\mathrm{EW}_{11} \mathrm{O}_{39}\right]^{(4+n)-}(n=3,4,5)$. The resulting compounds were characterized unambiguously by a combination of analytical methods, most importantly electro-spray ionization mass spectrometry (ESIMS) recorded in anion mode shown in Figure 1. For overview spectra, see Supporting Information, 


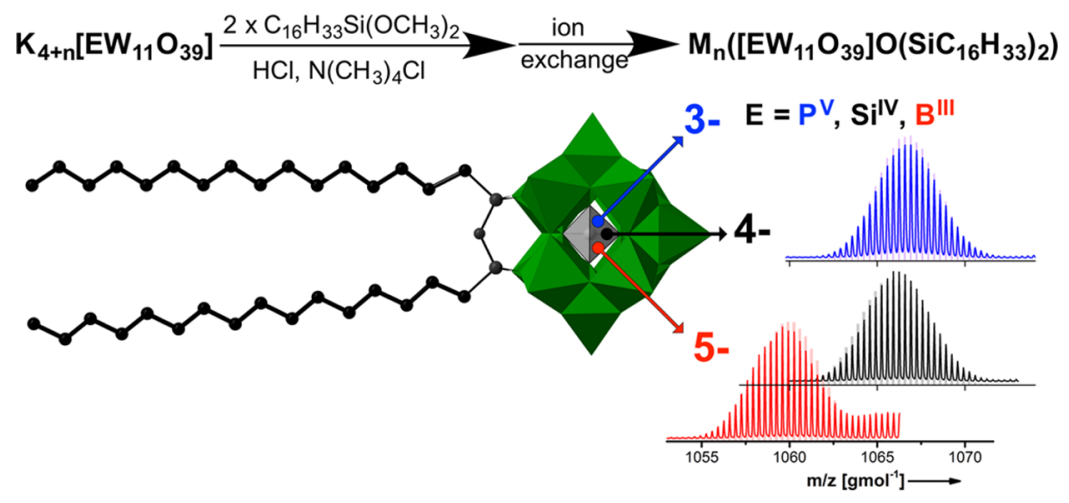

Figure 1. Top: Reaction sequence for the synthesis of surfactants with different heteropolytungstate head groups and systematically varying charge. $\mathrm{M}\left(\mathrm{Na}^{+}, \mathrm{H}^{+}\right)$. Middle: Molecular structure of the resulting surfactant (hydrogen atoms omitted) with the headgroup region highlighted in polyhedral plot (green $\cong \mathrm{WO}_{6}$ octahedra; gray $\cong \mathrm{EO}_{4}$ tetrahedron). Right: Main signals in ESIMS patterns for the compounds with different central atoms. P: blue graph $\cong$ experimental pattern; pale blue bars $\cong$ simulated pattern for $\left[\mathrm{C}_{32} \mathrm{H}_{66} \mathrm{Si}_{2} \mathrm{PW}_{11} \mathrm{O}_{40}\right]^{3-}$. Si: black graph $\cong$ experimental pattern; gray bars $\cong$ simulated pattern for $\mathrm{H}\left[\mathrm{C}_{32} \mathrm{H}_{66} \mathrm{Si}_{3} \mathrm{~W}_{11} \mathrm{O}_{40}\right]^{3-}$. B: red graph $\cong$ experimental pattern; pale red graph $\cong$ simulated pattern for $\mathrm{H}_{2}\left[\mathrm{C}_{32} \mathrm{H}_{66} \mathrm{Si}_{2} \mathrm{BW}_{11} \mathrm{O}_{40}\right]^{3-}$. Magnified images of the above signals are given in the Supporting Information Figures S-1, S-2, S-3.

Figures S-1 to S-3. One can identify several signals, which correspond to either the molecular ion or fragments having different charge due to attachment of cations (most importantly $\left.\mathrm{H}^{+}\right)$. The signals for the bare ions $\left[\mathrm{EW}_{11} \mathrm{O}_{40} \mathrm{Si}_{2} \mathrm{C}_{32} \mathrm{H}_{66}\right]^{n-}\left(n_{\mathrm{E}=\mathrm{P}}\right.$ $\left.=3 ; n_{\mathrm{E}=\mathrm{Si}}=4 ; n_{\mathrm{E}=\mathrm{B}}=5\right)$ are present, but they are relatively weak in intensity. Instead, the most intense signal was selected for detailed analysis in each of the cases (Figure 1). By comparison to theoretically modeled patterns, we see there is an agreement with the triply charged, partially protonated species. Please note that in such spectra, mass is divided by charge $z$. Thus, a signal at $1066.74 \mathrm{~g} \mathrm{~mol}^{-1}$ (average $\mathrm{m} / z$ ) for a charge of -3 represents a species with $\mathrm{M}=3200.22 \mathrm{~g} \mathrm{~mol}^{-1}\left(\mathrm{PW}_{11} \mathrm{C}_{16}\right)$. The charge can be determined from the distance between the isotope peaks. A distance of $1 / 3$ between each isotope peak as for the signals shown in Figure 1 indicates a charge of -3 . Supporting Information Figures S-1, S-2, S-3 summarize all additional spectroscopic data for $\mathrm{PW}_{11} \mathrm{C}_{16}, \mathrm{SiW}_{11} \mathrm{C}_{16}$, and $\mathrm{BW}_{11} \mathrm{C}_{16}$. $\mathrm{SiW}_{11} \mathrm{C}_{16}$ will be discussed here as an exemplary case: In ${ }^{29} \mathrm{Si}$ NMR (Figure S-2a,b), one observes two signals characteristic for the silicon atom in the center of the oxo-cluster $(\delta=-85$ $\mathrm{ppm})$ and the one attached to the hydrocarbon chain $(\delta=-52$ $\mathrm{ppm}$ ). Additionally, coupling between silicon and the different $\mathrm{W}$ atoms of the POM-cluster can be seen $\left({ }^{2} J_{\mathrm{Si}-\mathrm{W}}=10.3 \mathrm{~Hz}\right.$, $21.1 \mathrm{~Hz}$ ). The structure of the headgroup proposed in Figure 1 could also be proven by the characteristic $2: 2: 1: 2: 2: 2$ pattern and the ${ }^{2} J_{\mathrm{W}-\mathrm{W}}=10-20 \mathrm{~Hz}$ coupling constant in ${ }^{183} \mathrm{~W}-\mathrm{NMR}$ spectra (Figure S-2c). The observation of the mentioned nuclear coupling shows that the NMR experiments have been performed with high sensitivity. Because no unwanted signals are seen, we assume that there are no impurities present within the detection limit of NMR spectroscopy. Elemental analysis was aggravated by difficulties in drying/quantitative removal of any solvents used during synthesis (e.g., water). However, $\mathrm{CHN}$ values are in satisfactory agreement (e.g., for $\mathrm{TMA}_{4}\left[\mathrm{SiW}_{11} \mathrm{O}_{40}\left(\mathrm{SiC}_{16} \mathrm{H}_{33}\right)_{2}\right]$; C: $16.50 \%$ (calcd $16.31 \%$ ), $\mathrm{H}$ : $3.29 \%$ (calcd $3.49 \%), \mathrm{N}: 1.60 \%$ (calcd $1.78 \%)$ ); see also the Experimental Section.

${ }^{1} \mathrm{H}$ NMR, FT-Raman, and FT-IR spectra (Figure S-2d,f) are also in full agreement with the proposed structure of $\mathrm{SiW}_{11} \mathrm{C}_{16}$. Please note that cation exchange $\left(\mathrm{Na}^{+}, \mathrm{H}^{+}\right)$is necessary for increasing the solubility of the surfactants in water compared to the organic $\left(\mathrm{CH}_{3}\right)_{4} \mathrm{~N}^{+}$counterion originating from the first synthesis step (see Figure 1). The solubility with tetramethy- lammonium as a cation is less than $1 \mathrm{mg} / \mathrm{mL}$. After cation exchange (e.g. for $\mathrm{Na}^{+}$) solubility increases and is of the order of $100 \mathrm{mg} / \mathrm{mL}$. From spectroscopic data (see Supporting Information Figures S-1, S-2), one can conclude the cation exchange does not affect the integrity of the molecular structure of the surfactants at all.

Self-Assembly at High Concentration, Lyotropic Phases. After successful preparation and characterization of the $\mathrm{EW}_{11} \mathrm{C}_{16}$ compounds, it is time to explore their amphiphilic features with special emphasis on self-organized structures and the dependency on headgroup charge. First, we will focus on the high concentration regime resulting in LLCs. A dispersion containing $c_{0}=75 \%$ weight surfactant was used for the sample preparation (see also the Experimental Section). Agreeing with our previous results on this system, ${ }^{9}$ the $\mathrm{Na}-\mathrm{PW}_{11} \mathrm{C}_{16}$ surfactant forms phases which are typical for lyotropic liquid crystals. The LLC character can be seen from birefringence in optical microscopy between crossed polarizers (POLMIC) (see Figure $2 a$ ). The so-called smokey/mosaic texture is in agreement with a hexagonal phase. In transmission electron microscopy (TEM) images taken from dried samples, one can observe a nicely ordered structure comprising cylindrical aggregates arranged in a hexagonal packing $\mathrm{P6} / \mathrm{mm}$ (Figure $2 \mathrm{~b}$ ), which is a common LLC phase. Results from small-angle X-ray scattering (SAXS) shown in Figure $2 c$ confirms the latter. The periodicity of the hexagonal system is $a=4.2 \mathrm{~nm}\left(q=1.49 \mathrm{~nm}^{-1}\right)$. If we consider that the extension of a single surfactant is roughly $3.0 \mathrm{~nm}$, one has to assume there is partial interdigitation of the alkyl chains in the cylindrical aggregates, which is also not unusual in LLC phases.

Next, we want to discuss $\mathrm{SiW}_{11} \mathrm{C}_{16}$ used at otherwise constant conditions ( $c_{0}=75 \%$ weight; $\mathrm{Na}^{+}$as a counterion). The headgroup charge of the surfactant has increased to "4-". A first assessment-if the change in headgroup charge has an influence-can be done using POLMIC (Figure 2d). In addition, $\mathrm{SiW}_{11} \mathrm{C}_{16}$ forms LLCs. The observed texture is different compared to $\mathrm{Na}-\mathrm{PW}_{11} \mathrm{C}_{16}$. The silicon derivative shows features which are typical for a lamellar system. ${ }^{16}$ This is in agreement with SAXS measurements (Figure $2 \mathrm{f}$ ) pointing to a lamellar substructure with a periodicity of $6.6 \mathrm{~nm}(q=0.94$ $\left.\mathrm{nm}^{-1}\right)$. The mentioned periodicity is substantially larger than for $\mathrm{Na}-\mathrm{PW}_{11} \mathrm{C}_{16}$ and is of the order of twice the extension of a single surfactant, which is quite typical for lamellar surfactant 


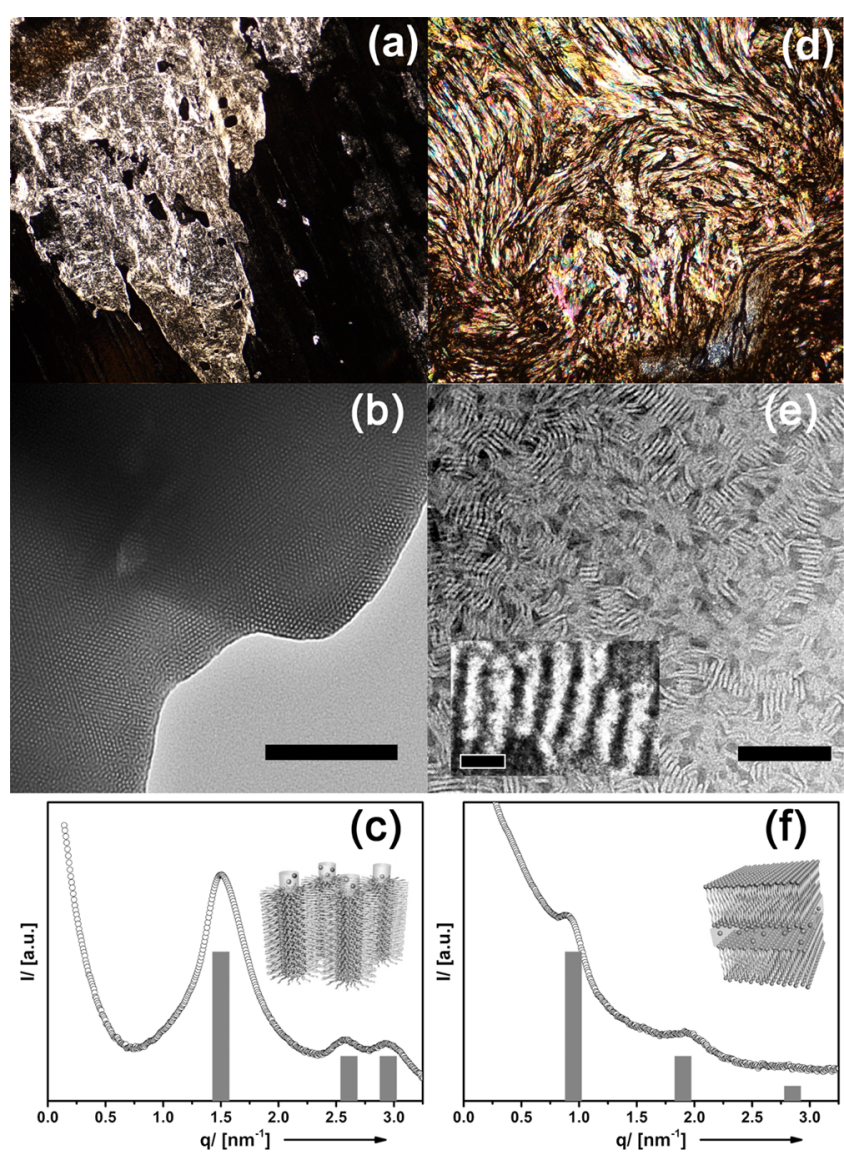

Figure 2. POLMIC (a), TEM (b; scale bar $100 \mathrm{~nm}$ ) and SAXS (c) data for the Na-PW ${ }_{11} \mathrm{C}_{16}$ surfactant at high concentration. POLMIC (d), TEM (e; scale bar $100 \mathrm{~nm}$, inlet: scale bar $10 \mathrm{~nm}$ ) and solid-state SAXS (f) data for the $\mathrm{Na}-\mathrm{SiW}_{11} \mathrm{C}_{16}$ surfactant at high concentration. Black bars mark the expected patterns for a cylindrical-hexagonal phase $P 6 / m m$ (c) and a lamellar phase $\operatorname{Im} 3 m$ (f), and the inset graphics show the suiting LLC phase.

structures. Unfortunately, the signals of the lamellar phase are relatively week and are superposed by an unspecific tail, which might indicate there is also a less structured, amorphous part of the sample. TEM measurements (Figure 2e) reveal that $\mathrm{Na}$ $\mathrm{PW}_{11} \mathrm{C}_{16}$ does not form a common lamellar phase with sheets extended in 2-D. The structure is unique: Objects with stripy, periodic features $(a=6.5 \mathrm{~nm})$ are identified, which are extended in one direction up to $150 \mathrm{~nm}$ (Figure 2e). However, we recognize several unusual features. For a lamellar phase it is unusual that confined rod-like growth is favored over extended 2-D growth, for example, into sheet-like structures. One should also note the extension of the self-organized aggregates perpendicular to the growth axis is fairly uniform $(\approx 10 \mathrm{~nm})$. Because of the large difference in electron density between the $\mathrm{W}$-containing head and the hydrocarbon side chains, one can easily differentiate between inorganic (dark) and organic (bright) regions in the structure. Considering the dimensions of the respective region, one can then speculate about how the surfactant is organized in the self-assembled structure. The size of the dark stripes is $\approx 2 \mathrm{~nm}$, according to evaluation of TEM data using the program ImageJ. For better visibility, a highresolution image was added as an inset in Figure 2e. Force-field calculations were done, pointing out that the extension of the head $\left[\mathrm{SiW}_{11} \mathrm{O}_{39}\right]$ headgroup with attached counterions is roughly $\sim 1 \mathrm{~nm}$. Thus, we assume a double-layer packing of the surfactants in the structure (see also Scheme 1).

The size of the bright stripes $(\approx 4.5 \mathrm{~nm})$ compared to the length of the alkyl-chains $\left(l_{\text {chain }} \sim 2.2 \mathrm{~nm}\right)$ provides evidence for a stretched conformation and the absence of any interdigitation. If the alkyl-chains would interpenetrate or were strongly bent, a significantly smaller value for the alkyl-region would have been expected. Similar patterns, as seen in Figure 2e, have been reported in the past for nanoparticles, for example, prismatic $\mathrm{BaCrO}_{4},{ }^{17}$ forming ordered chains induced by oriented attachment. ${ }^{18}$ Considering the various arguments, we propose the structure for the aggregates shown in Scheme 1a. Plate-like aggregates with a bilayer substructure stack, resulting in the "striped worms" and the overall lamellar architecture. The charge of the $\mathrm{Na}-\mathrm{BW}_{11} \mathrm{C}_{16}$ surfactant is even one unit higher (see Figure 1), and this seems to prevent any defined selforganization, at least under conditions chosen here. In POLMIC (given in Supporting Information Figure S-4a) one sees birefringent, fractal objects, that look similar to phases found for columnar thermotropic liquid crystals. However, in TEM (Figure S-4b) and SAXS (Figure S-4c), no particular structure is observed. Only seldom, and not very reproducibly, a spot with an unusual structure comprising triangular shapes (Figure S-4d) is found. Because of the lacking ability of $\mathrm{BW}_{11} \mathrm{C}_{16}$ to present well-defined LLC systems, we did not consider it for further studies.

Self-Assembly at Low Concentration, Micellization. For conventional surfactants we expect that in water, at lower concentrations $(c=10 \mathrm{mg} / \mathrm{mL})$ compared to the LLC phases but above a critical concentration $(\mathrm{cmc})$, micellar aggregates will be observed. This is exactly the case for $\mathrm{H}-\mathrm{PW}_{11} \mathrm{C}_{16}$, as shown in Figure 3a,c. Particle size distributions derived from dynamic light scattering measurements (DLS) show species with a hydrodynamic radius of $2.4 \mathrm{~nm}$, which fits well to spherical micelles composed of partially interdigitated surfactant molecules. TEM investigations confirm the latter finding (Figure 3c). Spherical, monodisperse objects with a diameter of $\approx 5 \mathrm{~nm}$ are found. All aggregates have a dark rim, which we assign to the high electron density of the $\left[\mathrm{PW}_{11} \mathrm{O}_{39}\right]$ head and the resulting imaging contrast. ${ }^{19}$ Enlarged TEM images can be found in Supporting Information Figure S-5.

In comparison, for $\mathrm{H}-\mathrm{SiW}_{11} \mathrm{C}_{16}$ there are only few aggregates found by DLS with sizes small enough for ordinary micelles. The major fraction is composed of larger objects $\left(R_{\mathrm{H}} \approx 16\right.$ $\mathrm{nm})$. The DLS data are consistent with TEM investigations (Figure $3 \mathrm{~d}$ ), which show objects with $\approx 25 \mathrm{~nm}$ in length and 5$7 \mathrm{~nm}$ in width. However, one can clearly see there is an asymmetric distribution of contrast (Figure 3e). Each aggregate has dumbbell shape with two zones of high electron density opposite to each other and an area of lower imaging contrast between. Kaya et al. have calculated theoretically the small angle scattering curves for dumbbell-like micelles. ${ }^{20}$ However, we were only able to fit the SAXS curve of $\mathrm{H}-\mathrm{PW}_{11} \mathrm{C}_{16}$ with a core-shell model (Figure 3f). Due to the very high electron density of the POM clusters forming the edge of the aggregate, the development of a "dumbbell core-shell model" would be of certain interest for the simulation of the SAXS curve obtained for $\mathrm{H}-\mathrm{SiW}_{11} \mathrm{C}_{16}$.

To the best of our knowledge, such a micellar morphology is unique. At higher magnification, the area in the middle seems to comprise a lamellar substructure (Figure 3e; bottom particle). Despite the fact the geometry of the $\mathrm{PW}_{11} \mathrm{C}_{16}$, $\mathrm{SiW}_{11} \mathrm{C}_{16}$, and $\mathrm{BW}_{11} \mathrm{C}_{16}$ surfactants is the same, undoubtedly 
Scheme 1. Image Illustrating the Proposed Intermolecular Interactions (Left) and the Structure of the Self-Assembled Aggregates at High Concentration (Middle) and Low (Right), with Lines Indicating an Electric Field Originating from the Respective Polyoxometalate Head Group Treated as a Point-Charge: (a) Shows the Situation for the Surfactant with Higher Charge $\left(\mathrm{SiW}_{11} \mathrm{C}_{16}\right)$ and $(\mathrm{b})$ Lower Charge $\left(\mathrm{PW}_{11} \mathrm{C}_{16}\right)^{a}$
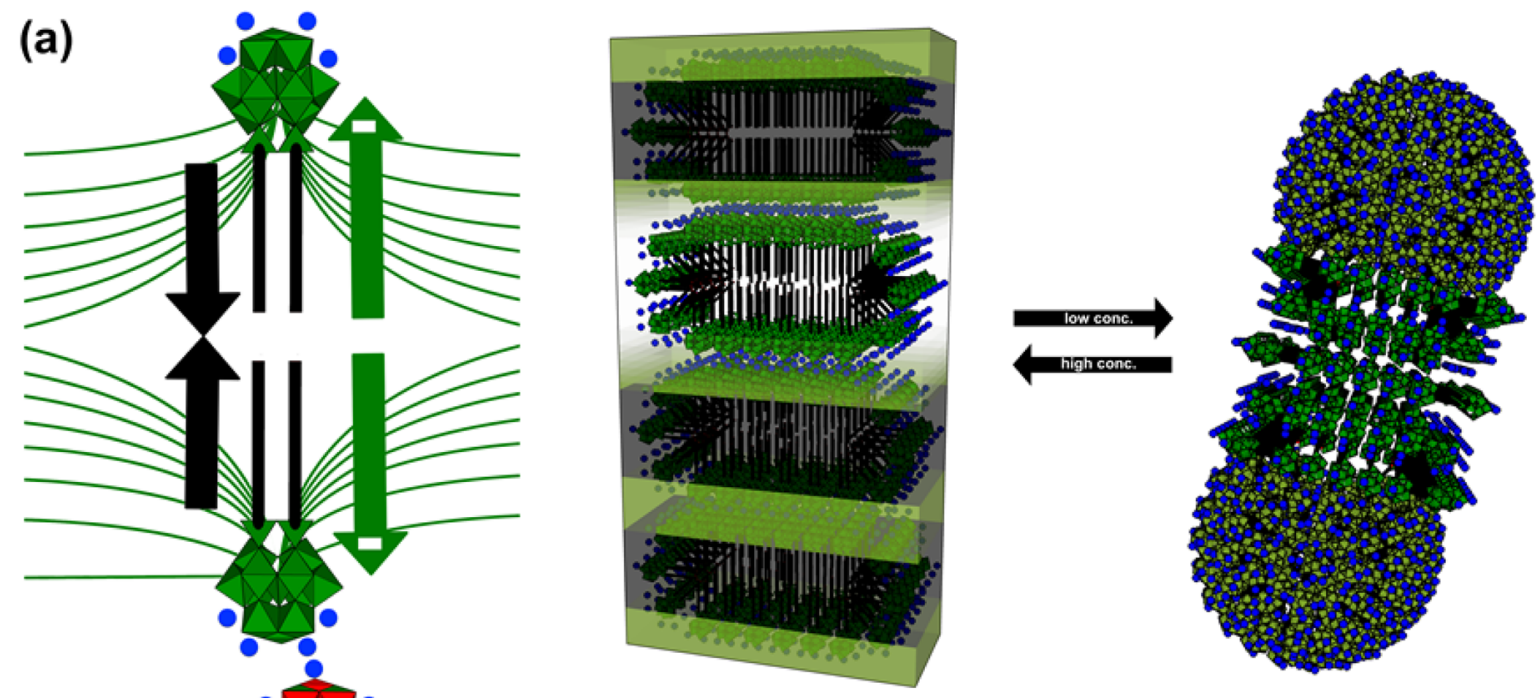

(b)

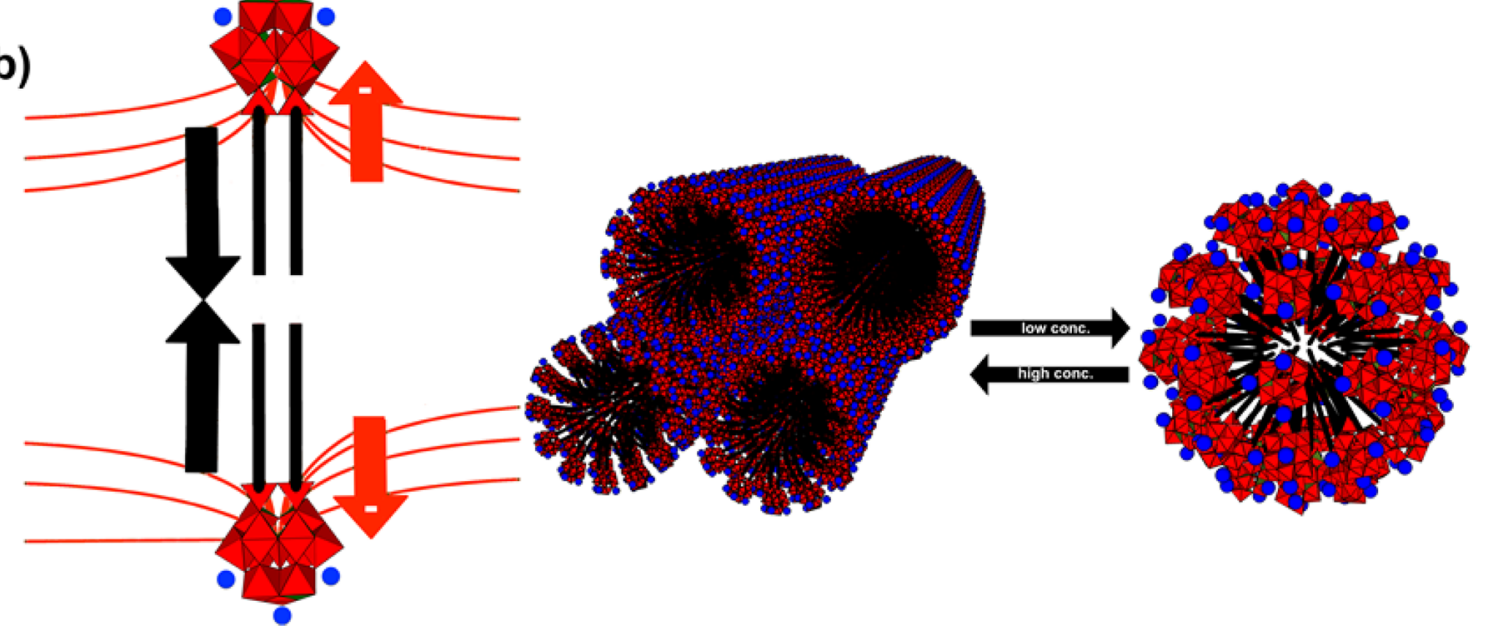

${ }^{a}$ Because the cations (shown in blue) cannot penetrate into the alkyl-phase (black), there is shielding of the field predominantly in one direction. The resulting electrostatic repulsion is plotted as either green or red vectors. Balance of repulsion with attractive forces (black vectors) determines the formation of the particular self-assembled structures. Regarding the structure of the self-assembled aggregates of $\mathrm{SiW}_{11} \mathrm{C}_{16}(\mathrm{a})$ at high concentration, see also Figure 2e, and at low concentration (dumbbell aggregates), see also Figure 3d,e. (b) Regarding the behavior for the lowercharged $\mathrm{PW}_{11} \mathrm{C}_{16}$ surfactant, see Figure $2 \mathrm{~b}$ for hexagonal LLC phases and Figure $3 \mathrm{c}$ for classical micelles in water.

the difference in headgroup charge leads to marked effects for the self-organization processes. $\mathrm{PW}_{11} \mathrm{C}_{16}$ with a headgroup charge of "3-" still behaves like an ordinary surfactant. It forms "ordinary" cylindrical LLC phases and at lower concentration in water spherical, micellar aggregates (Scheme $1 \mathrm{~b}$ ).

\section{SUMMARY AND CONCLUSIONS}

In the current contribution, we showed the synthesis and characterization of a series of three polyoxometalate surfactants with the same structure and dimensions but different charges: $\left[\mathrm{PW}_{11} \mathrm{C}_{16}\right]^{3-},\left[\mathrm{SiW}_{11} \mathrm{C}_{16}\right]^{4-}$, and $\left[\mathrm{BW}_{11} \mathrm{C}_{16}\right]^{5-}$. There is another important factor in aqueous POM-systems, which is cationmediated attraction. Is has been shown among others by $\mathrm{Liu}^{21}$ and Weinstock ${ }^{22}$ that self-assembly of POM clusters is affected by the counterions. Molecular dynamic simulations of Keggin clusters in acid aqueous environment performed by Chaumont and Wipff $^{23}$ also show that $\mathrm{SiW}_{12} \mathrm{O}_{40}{ }^{4-}$ exhibits a larger tendency of aggregation compared to $\mathrm{PW}_{12} \mathrm{O}_{40}{ }^{3-}$, despite its higher charge. Furthermore, they found that the distance between the aggregated clusters changes only marginally ( 0.1 $\AA$ ). Transferring these findings to our systems, one can conclude that our assumptions on the equality of the headgroup sizes of the herein-analyzed surfactants are correct. Despite the fact we cannot quantify the influence of cationmediated attraction, our assumptions are still valid as the systems comprise the same sort of cations in the compared lowand high-concentration regimes.

We investigated the formation of lyotropic structures in water at high and at low concentration. We found that there is a substantial influence of charge on the self-organization behavior. The self-assembly behavior for $\mathrm{PW}_{11} \mathrm{C}_{16}$, despite its charge of "3-", perfectly matched the structures one would expect for classical surfactants with the help of the concept of the "packing parameter". ${ }^{24}$ Unusual aggregates were found for head charge "-4" $\mathrm{SiW}_{11} \mathrm{C}_{16}$ (Figure 2e; Figure 3d,e). When the 

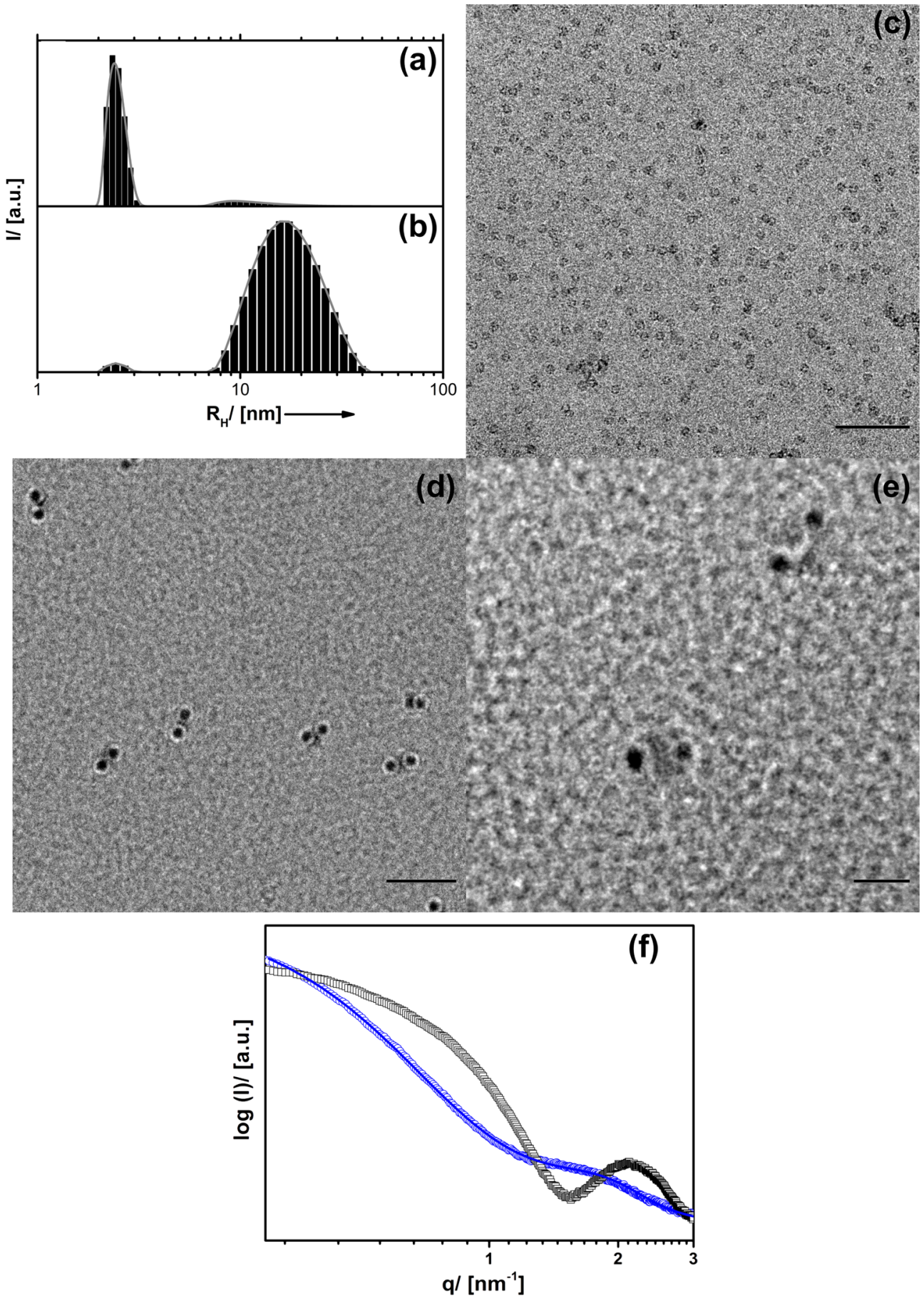

Figure 3. DLS measurements of aqueous dispersions $(c=10 \mathrm{mg} / \mathrm{mL})$ of the H-PW $\mathrm{PW}_{11} \mathrm{C}_{16}$ surfactant $(\mathrm{a})$ and of the $\mathrm{H}-\mathrm{SiW}_{11} \mathrm{C}_{16}$ surfactant $(\mathrm{b})$. TEM micrograph of a $\mathrm{H}-\mathrm{PW}_{11} \mathrm{C}_{16}$ micellar dispersion (c) and of aggregates formed by $\mathrm{H}-\mathrm{SiW}_{11} \mathrm{C}_{16}$ in water at two different magnifications; scale bar = 50 $\mathrm{nm}(\mathrm{d})$, scale bar $=25 \mathrm{~nm}$ (e). (f) SAXS data recorded from aqueous dispersions of $\mathrm{H}-\mathrm{PW}_{11} \mathrm{C}_{16}$ (blue circles), fitted using a spherical core-shell model (blue line) and $\mathrm{H}-\mathrm{SiW}_{11} \mathrm{C}_{16}$ (black squares).

headgroup charge is even higher, as for $\mathrm{BW}_{11} \mathrm{C}_{16}$, it was pointed out the emergence of ordered aggregates is aggravated.

Although we cannot give a precise physical picture of the interactions and thermodynamics leading to the unusual phenomena, we want to discuss some ideas and check if they are in-line with existing theories on surfactant self-assembly. These ideas are also summarized in Scheme 1. Considering the inspiring seminal work of Grzybowski and co-workers on nanoparticle self-assembly, ${ }^{25}$ one condition for achieving unprecedented modes of self-assembly is the existence of competing attractive and repulsive forces. The attractive forces in the current molecular system are of course the interaction of the head with cations and the van der Waals/hydrophobic interactions between the alkyl-chains, just like in any other surfactant system. ${ }^{26}$ As classical surfactants carry only a low headgroup charge, the electrical field is too weak to result in a substantial repulsive force. The electrical field originates from unshielded charge, caused by the unbalanced distribution of the counter cations around the POM headgroup, as they cannot be situated in the hydrophobic domains of the aggregate. As a 
consequence, one observes known structures dictated by the attractive interactions. As such compact and highly charged surfactants like described in our work were not considered when Israelachvili and co-workers published their popular work, is not surprising that our systems exceed the limitations of the packing parameter. As a very rough model, we consider the electric field resulting from a polyoxometalate cluster treated as an isolated point-charge fixed of a surface (of an dielectric medium of low polarizability) immersed in an electrolyte with a Helmholtz-type layer of cations attached to the headgroup. The contribution of the attractive, hydrophobic interactions is constant in both systems $\left(\mathrm{PW}_{11} \mathrm{C}_{16}\right.$ and $\mathrm{SiW}_{11} \mathrm{C}_{16}$, indicated by black arrows in Scheme 1). Whereas the repulsive electrostatic force (green and red arrows) grows stronger with a higher charge of the surfactant and eventually crosses the threshold repulsive interaction starts influencing the self-assembly behavior. Because of a high headgroup charge, it would be favorable for $\mathrm{SiW}_{11} \mathrm{C}_{16}$ also at high concentration to form curved structures, which militates against a classical lamellar phase. Besides, the high charge could also increase the packing parameter of the surfactant, and this is also a factor favoring curved aggregates. Due to the described electrostatic repulsion, $\mathrm{SiW}_{11} \mathrm{C}_{16}$ cannot adopt cylindrical aggregates as easily as this would require interdigitation of the alkyl-chains and thus a smaller distance between the negative poles, which is obviously disadvantageous. Thus, the bilayer aggregates can be seen as a compromise between a cylindrical structure and a lamellar phase. It can be argued that at lower concentration, water molecules might penetrate the interlayer space comprising the POM heads and their counterions. The bisection of the lamellar structure and reorganization of the aggregates is the result (see Scheme 1a). The solvation of the cations leads to a further increase of the packing parameter, and normally a micelle, the structure with the maximum curvature, is formed (Scheme $1 \mathrm{~b}$ ). Because of the same reasons given above, $\mathrm{SiW}_{11} \mathrm{C}_{16}$ can also not exist in the state of spherical micelles so easily, and again one can rationalize the emergence of a new pattern (Figure $3 \mathrm{~d}, \mathrm{e}$ ) caused by the necessary compromise. The process can be thought to result from the transition of the bilayer plates on its two flat sides, which could explain the symmetry of the dumbbell objects, the overall extensions of those particles, and the central, lamellar subdomain with weak electron contrast (Scheme $1 \mathrm{~b}$, right image). This morphology is distinct from dumbbell micelles for purely organic systems described in some theoretical predictions, but there are similarities. For instance, Leermakers predicted anisotropic, elongated micelles, if the length of the alkyl-chain is small, which could lead to an enhanced repulsion between the heads in an aggregate. ${ }^{27}$ Disher et al. argue the formation of dumbbell micelles can be the effect of a curvature-driven nanophase separation. ${ }^{28}$ This model is of course oversimplifying the real situation, but, unfortunately, quantitative calculations would require sophisticated ab initio calculation, which can only be done by specialists.

\section{ASSOCIATED CONTENT}

\section{S Supporting Information}

The Supporting Information is available free of charge on the ACS Publications website at DOI: 10.1021/acs.langmuir.6b02661.

Additional analytical data for the characterization of the surfactants (PDF)

\section{AUTHOR INFORMATION}

\section{Corresponding Author}

*E-mail: sebastian.polarz@uni-konstanz.de.

\section{Author Contributions}

The manuscript was written through contributions of all authors. All authors have given approval to the final version of the manuscript.

\section{Funding}

The current research was funded by an ERC consolidator grant (I-SURF; project 614606).

\section{Notes}

The authors declare no competing financial interest.

\section{REFERENCES}

(1) Whitesides, G. M.; Grzybowski, B. Self-Assembly at All Scales. Science 2002, 295 (5564), 2418.

(2) Ozin, G. A.; Hou, K.; Lotsch, B. V.; Cademartiri, L.; Puzzo, D. P.; Scotognella, F.; Ghadimi, A.; Thomson, J. Nanofabrication by selfassembly. Mater. Today 2009, 12 (5), 12-23.

(3) Grzybowski, B. A.; Wilmer, C. E.; Kim, J.; Browne, K. P.; Bishop, K. J. M. Self-assembly: from crystals to cells. Soft Matter 2009, 5 (6), $1110-1128$.

(4) Cademartiri, L.; Bishop, K. J. M. Programmable self-assembly. Nat. Mater. 2015, 14 (1), 2-9.

(5) Tschierske, C. Development of Structural Complexity by LiquidCrystal Self-assembly. Angew. Chem., Int. Ed. 2013, 52 (34), 88288878.

(6) Faul, C. F. J.; Antonietti, M. Ionic self-assembly: Facile synthesis of supramolecular materials. Adv. Mater. 2003, 15 (9), 673-683.

(7) Zhang, X.; Wang, C. Supramolecular amphiphiles. Chem. Soc. Rev. 2011, 40 (1), 94-101.

(8) Polarz, S.; Landsmann, S.; Klaiber, A. Hybrid Surfactant Systems with Inorganic Constituents. Angew. Chem., Int. Ed. 2014, 53 (4), 946954.

(9) Landsmann, S.; Lizandara-Pueyo, C.; Polarz, S. A New Class of Surfactants with Multinuclear, Inorganic Head Groups. J. Am. Chem. Soc. 2010, 132 (14), 5315-5321.

(10) Landsmann, S.; Luka, M.; Polarz, S. Bolaform surfactants with polyoxometalate head groups and their assembly into ultra-small monolayer membrane vesicles. Nat. Commun. 2012, 3, 1299.

(11) Landsmann, S.; Wessig, M.; Schmid, M.; Coelfen, H.; Polarz, S. Smart Inorganic Surfactants: More than Surface Tension. Angew. Chem., Int. Ed. 2012, 51 (24), 5995-5999.

(12) Dolbecq, A.; Dumas, E.; Mayer, C. R.; Mialane, P. Hybrid Organic-Inorganic Polyoxometalate Compounds: From Structural Diversity to Applications. Chem. Rev. 2010, 110 (10), 6009-6048.

(13) Contant, R. Comparative-study of tungstophosphates related to the $\mathrm{PW}_{12} \mathrm{O}_{40}{ }^{3-}$ anion - synthesis and properties of $\mathrm{K}_{10} \mathrm{P}_{2} \mathrm{~W}_{20} \mathrm{O}_{70} \bullet 24 \mathrm{H} 2 \mathrm{O}$, a new lacunary polyoxotungstophosphate. Can. J. Chem. 1987, 65 (3), 568-573.

(14) A. Tézé, G. H. Introduction to Early Transition Metal Polyoxoanions. In Inorganic Syntheses; Ginsberg, A. P., Ed.; John Wiley \& Sons, Inc.: Hoboken, NJ, 1990; pp 85-96.

(15) Teze, A.; Michelon, M.; Herve, G. Syntheses and structures of the tungstoborate anions. Inorg. Chem. 1997, 36 (4), 505-509.

(16) Martin, J. D.; Keary, C. L.; Thornton, T. A.; Novotnak, M. P.; Knutson, J. W.; Folmer, J. C. W. Metallotropic liquid crystals formed by surfactant templating of molten metal halides. Nat. Mater. 2006, 5 (4), 271-275.

(17) Li, M.; Schnablegger, H.; Mann, S. Coupled synthesis and selfassembly of nanoparticles to give structures with controlled organization. Nature 1999, 402 (6760), 393-395.

(18) Niederberger, M.; Colfen, H. Oriented attachment and mesocrystals: Non-classical crystallization mechanisms based on nanoparticle assembly. Phys. Chem. Chem. Phys. 2006, 8 (28), 32713287. 
(19) Giner-Casares, J. J.; Brezesinski, G.; Mohwald, H.; Landsmann, S.; Polarz, S. Polyoxometalate Surfactants as Unique Molecules for Interfacial Self-Assembly. J. Phys. Chem. Lett. 2012, 3 (3), 322-326.

(20) Kaya, H. Scattering from cylinders with globular end-caps. J. Appl. Crystallogr. 2004, 37, 223-230.

(21) Yin, P.; Li, D.; Liu, T. Solution behaviors and self-assembly of polyoxometalates as models of macroions and amphiphilic polyoxometalate-organic hybrids as novel surfactants. Chem. Soc. Rev. 2012, 41 (22), 7368-83.

(22) Wang, Y.; Zeiri, O.; Sharet, S.; Weinstock, I. A. Role of the alkali-metal cation size in the self-assembly of polyoxometalatemonolayer shells on gold nanoparticles. Inorg. Chem. 2012, 51 (14), $7436-8$.

(23) Chaumont, A.; Wipff, G. Interactions between Keggin Anions in Water: The Higher Their Charge, the Higher Their Condensation? A Simulation Study. Eur. J. Inorg. Chem. 2013, No. 10-11, 1835-1853. (24) Israelachvili, J. N.; Mitchell, D. J.; Ninham, B. W. Theory of selfassembly of hydrocarbon amphiphiles into micelles and bilayers. $J$. Chem. Soc., Faraday Trans. 2 1976, 72, 1525-1568.

(25) Kalsin, A. M.; Fialkowski, M.; Paszewski, M.; Smoukov, S. K.; Bishop, K. J. M.; Grzybowski, B. A. Electrostatic self-assembly of binary nanoparticle crystals with a diamond-like lattice. Science 2006, 312 (5772), 420-424.

(26) Meyer, E. E.; Rosenberg, K. J.; Israelachvili, J. Recent progress in understanding hydrophobic interactions. Proc. Natl. Acad. Sci. U. S. A. 2006, 103 (43), 15739-15746.

(27) Jodar-Reyes, A. B.; Leermakers, F. A. M. Self-consistent field modeling of linear nonionic micelles. J. Phys. Chem. B 2006, 110 (12), 6300-6311.

(28) Loverde, S. M.; Ortiz, V.; Kamien, R. D.; Klein, M. L.; Discher, D. E. Curvature-driven molecular demixing in the budding and breakup of mixed component worm-like micelles. Soft Matter 2010, 6 (7), 1419-1425. 